\title{
DINÂMICAS URBANAS E A PRESENÇA FEMININA NA SÃO PAULO DA PRIMEIRA METADE DO SÉCULO XIX (1820-1841)*
}

\author{
Thiago Pereira Majolo \\ Mestrando em História Social - FFLCH/USP
}

\section{Resumo}

Partindo de uma análise sobre a Câmara Municipal de São Paulo na primeira metade do século XIX, o artigo procura inserir na vida cotidiana da instituição micro-histórias de personagens femininas aparentemente excluídas da história política paulista, a fim de demonstrar a complexidade de temas como o debate da historiografia de gênero, as relações entre poder social e político e a legitimidade e a eficácia das leis.

\section{Pallavras-Chave}

São Paulo • Mulheres • Gênero • Século XVIII • Câmara Municipal

\section{Abstract}

Starting from an analysis about the São Paulo's Common Council at the first half of XIX century, the article intend to introduce in the institution's routine micro-stories of female characters that seems to be excluded from the city's political history, in order to show the complexity of themes like the gender's historiography debate, the relation between political and social power and the law's legitimacy and the effectiveness.

\section{Keywords}

São Paulo $\bullet$ Women $\bullet$ Gender $\bullet$ XVIII Century $\bullet$ Common Council

\footnotetext{
* O presente artigo faz parte de Pesquisa de Iniciação Científica, intitulada "Demandas e Querelas: as mulheres e o poder local em São Paulo no século XIX (1820-1841)”, financiada pela FAPESP no ano de 2005, sob a orientação da Profa. Dra. Maria Cristina Cortez Wissenbach.
} 
O fim da década de 1820 e o começo da posterior foram anos agitados para a Câmara Municipal de São Paulo. Na cidade, pequenos acontecimentos cotidianos e aparentemente banais, unidos a transformações legislativas em nível imperial, obrigaram a administração a trabalhar intensamente e se adaptar a novas conjunturas.

\section{Focando a Câmara Municipal Paulista}

Em tese, a Câmara Municipal, mesmo sob julgo do poder provincial e do imperial era responsável pela coordenação de certas instâncias financeiras, legislativas, políticas e sociais. ${ }^{1}$ Principalmente em uma cidade tão pequena como a São Paulo oitocentista, as funções da administração municipal e de seus funcionários, como o controle fiscal, a vigilância, a aplicação de leis e outras pareciam ser facilitadas tanto pela proximidade entre camaristas e a população, quanto pela baixa densidade demográfica. Pensando da mesma forma, podemos ter a impressão de que as atividades administrativas não passavam de uma mera prestação de serviços essencialmente burocráticos e quase monótonos. Se, além disto, acreditarmos também em uma possível sedimentação dos poderes institucionais, isto é, na maior separação entre esferas pública e privada - o que sugere parte da historiografia sobre o século XIX brasileiro - a Câmara Municipal Paulista, teoricamente, parecia ter vida mansa.

Ademais, quando nos deparamos com os nomes dos vereadores, não vamos encontrar nesta época nada além de homens ricos ou remediados, com grandes propriedades de terras e influência política, sendo na maioria brancos. De fato, se concebermos o fazer político pela formação intelectual destinada ao trabalho nas instituições de poder, somente estes grupos sociais de pessoas poderiam considerar-se políticos na cidade de São Paulo oitocentista, uma vez que este nível de formação intelectual só podia ser alcançado por homens minimamente bem posicionados. Nesta visão, a Câmara paulista e os seus funcionários parecem muito restritos, fechados em si mesmos e nos seus trabalhos.

\footnotetext{
${ }^{1}$ Sobre o poder provincial paulista da primeira metade do século XIX, ver: DOLHNIKOFF, Miriam. Caminhos da conciliação - o poder provincial em São Paulo (1835-1850). São Paulo: Dissertação de Mestrado, Departamento de História-FFLCH/USP, 1993. Para uma análise resumida da organização administrativa brasileira, ver: BARROS, Liliane Schrank Lehmann \& MOIZO, Rosana Pires Azanha. "Formação administrativa da cidade de São Paulo, 1554 - 1954”. Revista do Arquivo Municipal, São Paulo, volume 199, 1991.
} 
Mas esta é somente uma vista panorâmica da maior parte do século XIX paulista. Trata-se uma espécie de imagem aérea, distante, como se fosse uma fotografia de época, na qual tudo parece bem assentado, e o dinamismo das ruas torna-se borrões diante das lentes ainda incapazes de captar precisamente o movimento. ${ }^{2}$ As características desta imagem são provenientes de uma escala muito grande ou de uma lente muito inadequada para compreender e interpretar a aparente banalidade dos acontecimentos e a sutileza das transformações desta cidade oitocentista tão provinciana. A intimidade das relações entre seus habitantes faz com que aquela São Paulo peça ao seu observador não uma lente fotográfica, mas um microscópio. ${ }^{3}$

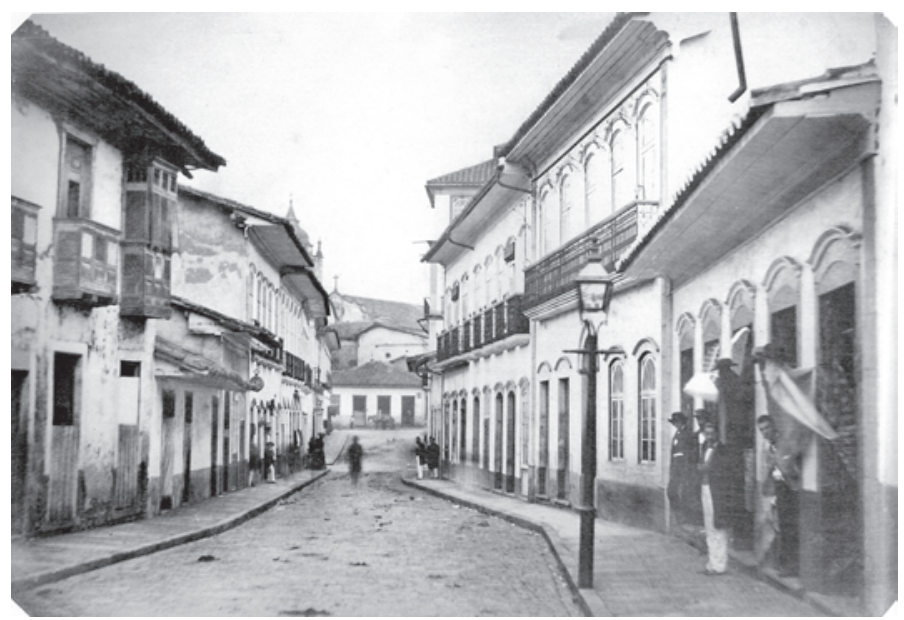

Rua do Rosário, 1862/63 (Militão Augusto de Azevedo). Detalhe das imagens borradas das pessoas. Os borrões nas fotografias de época, que ocorriam por culpa das lentes de então ainda incapazes de focar pessoas ou objetos em movimento, diz muito sobre o imaginário que se criou sobre a cidade oitocentista. Uma vez que as únicas figuras nítidas são as que estavam paradas no momento do registro, vincula-se à cidade uma noção de monotonia. ${ }^{4}$

\footnotetext{
${ }^{2}$ Os primeiros registros fotográficos da cidade oitocentista, elaborados pelo Militão Augusto de Azevedo retratam a São Paulo da década de 1860. Contudo, comparando as fotografias com outros registros iconográficos mais antigos, podemos entender que Militão Augusto retratava a vida de uma cidade muito parecida com a do começo do século. Portanto, para fins práticos, tomarei a liberdade de usar as fotografias da década de 1860 do Militão de Azevedo como uma expressão bastante aproximada da cidade das décadas de 1820, 1830 e 1840.

${ }^{3}$ Sobre a importância da escolha de escala na análise científica, ver: LEPETIT, Bernard. "Sobre a escala da História". In: REVEL, Jacques (org.). Jogos de escalas - a experiência da microanálise. Rio de Janeiro: Fundação Getúlio Vargas, 1998.

${ }^{4} \mathrm{~A}$ idéia de ampliar as imagens para tentar enxergar os borrões é muito bem traduzida no trabalho: LAGO, Pedro Correa do. Militão Augusto de Azevedo. Rio de Janeiro, Ed. Capivara, 2001, p. 64.
} 


\section{Entrando no prédio}

Se nesta exploração mais minuciosa começarmos por adentrar o prédio da Câmara Municipal da cidade, exatamente no ano de 1828, certamente enxergaremos alguma balbúrdia entre os vereadores. Apesar da Constituição de 1824 ter dado a impressão que garantiria mais independência tanto à unidade provincial, quanto à municipal, a Lei de $1828,{ }^{5}$ pouco depois ceifou parte da força dos municípios, garantindo maior controle somente às províncias. ${ }^{6}$ Aos vereadores municipais restou um trabalho mais resumido aos encargos administrativos, cujo alcance e calibre eram pequenos.

Impotentes para legislar, a Câmara utilizou-se de dispositivos tais como as Posturas Municipais na busca de certo controle social. As primeiras posturas, publicadas em 1820, foram um compêndio ainda tímido de regras para se bem viver na cidade, e certamente seu texto oficial não passou livre de transformações e interpretações realizadas por uma população que contava com altos níveis de analfabetismo e uma cara tradição oral. Apesar do desconhecimento e dos descompromissos que a imensa maioria demográfica tinha para com a lei, em 1828 os vereadores, atados para ambições maiores, começaram a formar uma Comissão de Revisão dos Códigos de Postura a fim de aperfeiçoar uma das suas poucas armas de manutenção das leis urbanas. A revisão termina em 1830, ano em que o texto dos Códigos ganha seu segundo formato, maior, mais denso e rígido. ${ }^{7}$

O trabalho camerário, então, se intensificou. As Atas da Câmara, a partir deste ano, passaram a compreender volumes mais generosos nos quais o cotidiano da cidade, juntamente com os primeiros esboços da revisão dos Códigos de Postura, engrossam os registros municipais. Enfraquecidos pela Lei de 1828, os camaristas pareciam mais preocupados com os problemas rotineiros. Para tais questões cotidianas, os vereadores lançavam mão de um mediador entre eles e a população designado por Juiz de Paz, cargo criado pela Constituição de 1824. Funcionários municipais não remunerados, eleitos a cada quatro anos

\footnotetext{
${ }^{5}$ A Lei de 1828, seguindo a intenção centralizadora de D. Pedro I, regulou a administração municipal, restringindo a esfera de poder dos vereadores, que ficaram ainda mais subordinados ao presidente da província.

${ }^{6}$ DOLHNIKOFF, Miriam. Op.cit. pp. 3 a 14.

${ }^{7}$ Sobre o tema das posturas municipais, ver: MARINS, Paulo César Garcez. Através da rótula: sociedade e arquitetura urbana no Brasil, séculos XVII-XX. São Paulo: Tese de Doutorado, Departamento de História-FFLCH/USP, 1999.
} 
pela Câmara, que serviam de mediadores de querelas e desacertos entre a população, os Juizes de Paz procuravam antes mediar o conflito, resolvendo-o na esfera pessoal, a aplicar a lei. Bem verdade é que nem mesmo eles conheciam a lei por completo, pois, trabalhando em outros serviços, não tinham tempo nem interesse em estudar a legislação. Tampouco, também, eram idôneos na resolução das causas a que eram chamados a mediar, uma vez que seus interesses pessoais, principalmente em níveis comerciais, eram mais imperativos que a parcialidade de seus julgamentos. Por estes motivos, os Juízes de Paz nunca receberam da população a legitimidade e a confiança ideais. ${ }^{8}$

Principalmente a partir de 1828, a Câmara Municipal, enfraquecida e sem contar plenamente com a força destinada aos Juízes de Paz, começa a conviver mais intimamente com o dinamismo das ruas. As vereanças, então, tornam-se caóticas, bagunçadas, perdidas em um turbilhão de requerimentos, brigas, infrações, conchavos políticos entre outros acontecimentos urbanos. Quando a Câmara resolveu atentar e descrever mais minuciosamente as pequenas banalidades do dia-a-dia, elas invadiram o prédio dos vereadores e contaram muitos trechos de histórias de vida. Dispersos na confusão dos documentos camerários, a reunião destes trechos forma um quebra-cabeça que, mesmo despedaçado, permite vislumbrar imagens em formação e intuir com certo grau de precisão ilustrações do cotidiano paulista. É exatamente como se em alguns pontos dos borrões das fotografias de época a imagem ganhasse foco e, aos poucos, delineasse uma forma mais conhecida e compreensível para os olhos do observador.

\section{Focando os borrões}

Dona Maria Clara Gomes, mulher paulista provavelmente bem remediada, resolvera reformar a sua casa. Ignorando ou desconhecendo as exigências do Código de Posturas de 1820, transformou a sua residência da maneira que mais lhe agradava. A transformação, contudo, não agradou a Câmara. No dia 8 de março de 1828, a fiscalização municipal denunciou que a nova arquitetura da casa de Dona Maria Clara Gomes deixara a sua rua por demais estreita. ${ }^{9}$ Como a preocupação com o trânsito das calçadas era uma das grandes questões que a

\footnotetext{
${ }^{8}$ Sobre o tema, ver: FLORY, Thomas. Judge and jury in imperial Brazil. 1808 - 1871 - social control and political stability in the new state. Austin, Texas: University of Texas press, 1981.

${ }^{9}$ Arquivo Municipal Washington Luís, Papéis Avulsos, etiqueta 27, páginas 208-212.
} 
administração revelava já nas Posturas de 1820 - e que se acentuaria mais adiante a infração desta mulher parecera grave. O plano urbanístico para construção de uma cidade mais dinâmica, mais preparada para um possível adensamento demográfico ou para outras futuras conjunturas igualmente imprevisíveis, era assunto corrente nas vereanças paulistas oitocentistas, principalmente a partir de 1828.

Perseguindo o seu projeto, a Câmara confiou na sua fiscalização. Mesmo tendo flagrado diversos delitos, os fiscais ainda eram incapazes de cobrir todas as ilegalidades. A lei previa multas para infratores, assim como também reservava um curioso método de atuação quando a infração concernia os cuidados com o imóvel: se fosse constatada alguma irregularidade, o infrator deveria cumprir a lei por conta própria ou funcionários da Câmara resolveriam o problema, e a despesa seria cobrada do proprietário. Quando o caso tornava-se insolúvel, medidas mais drásticas eram tomadas, como aconteceu quando os vereadores cansaram-se de inquilinos pobres e inadimplentes da ladeira do Carmo. No dia 7 de maio do mesmo ano de 1828, foi lida uma ordem de despejo para vários moradores da rua. Não somente as dívidas contaram para que os inquilinos fossem obrigados a deixar suas casas. ${ }^{10}$ Eles não tinham, provavelmente, condições financeiras para manter suas residências conforme exigiam os Códigos de Postura. Antes de doar um terreno, a Câmara, se desconfiasse da incapacidade financeira de quem receberia a terra, mandava verificar a possibilidade daquela pessoa em se manter segundo as leis urbanas. É claro que desta demanda somada a outras conjunturas como o crescente mercado imobiliário oitocentista, decorre o fato do êxodo constante e progressivo de pessoas pobres para regiões em que a fiscalização fosse mais amena e a preocupação camerária com a aparência citadina fosse de menores proporções.

Os novos proprietários, por sua vez, requeriam terras para a Câmara. As doações de terreno, chamadas Cartas de Datas, nas quais a municipalidade delimitava o tamanho do terreno, a localização, o proprietário entre outras características, no século XIX já abrangiam lugares mais distantes do Triângulo Central. Conta disto é a escassez de terrenos nesta região. Em 1809, ano da Décima Urbana (primeiro imposto predial brasileiro), menos de 30 lotes e apenas 1 terreno não estavam ocupados nesta área. Foi o início, ainda incipientemente, do crescimento de outros bairros, principalmente os pobres, como o

\footnotetext{
${ }^{10}$ AMWL, Atas da Câmara, volume XXIV, páginas 169-170.
} 
Brás. Abordando por outro viés, vê-se que a Câmara detinha uma parcela de terras na região central que apesar de grande, já não era a maior. Além de perder em quantidade de terrenos para a igreja católica, ainda havia proprietários particulares como Dona Marianna Fortes ou o Capitão Gabriel José Roiz que eram mais atuantes no mercado imobiliário. ${ }^{11}$

Se por um lado a Câmara Municipal já não era a maior possuidora de terras, a partir de 1828 ela também começava a se atrapalhar na distribuição das Cartas de Datas. Devido à confusão crescente nas vereanças e a perda de poder municipal, os processos da instituição tornam-se mais lentos e burocratizados. Em 29 de novembro do ano de 1828, Izabel Umbelina de Oliveira requereu uma Carta de Data de um terreno. De fato, ela vai conseguir esta carta no dia 6 de dezembro do mesmo ano. ${ }^{12}$ Seu processo é muito rápido, mas já não conta com a mesma momentaneidade de processos de anos anteriores. A partir de então, o que se vê nas Atas da Câmara é uma crescente demora nos processos. Meses, por vezes quase um ano se passa enquanto que o requerimento é prorrogado, mandado para outra comissão, aprovado ou não para depois retornar à Câmara Municipal que por fim encerra o caso após mais algumas exigências burocráticas. Este é o caso de Dona Gertrudes Maria de Siqueira, que, ao requerer um terreno contíguo aos valos de Dona Anna Josepha, que fazia frente à estrada que ia para Lavapés, viveu todo o processo burocrático que se instalara no dia-a-dia cada vez mais turbulento da Câmara. Seu primeiro pedido aconteceu dia 11 de janeiro de 1830. Nesta tentativa, ela só obteve a seguinte resposta: que seu pedido seria deferido a seu tempo. Não satisfeita de esperar pelo seu tempo, Dona Gertrudes Maria Siqueira volta a pedir o terreno no dia 16 de março do mesmo ano. Desta vez a requerente consegue que seu pedido seja remetido à Comissão Permanente, de onde voltava resolvida grande parte dos requerimentos. A Comissão atende seu pedido em 17 de abril e em 19 do mesmo mês é lido ao fiscal um ofício sobre o requerimento. Assim sendo, em 7 de agosto é feita uma vistoria no terreno, mas no parecer aparecem constatadas algumas restrições à demanda de Dona Gertrudes. Ela, portanto, espera até

\footnotetext{
${ }^{11}$ Sobre a questão do mercado imobiliário da São Paulo oitocentista, ver: BUENO, Beatriz Piccolotto Siqueira. Tecido urbano e mercado imobiliário em São Paulo: metodologia de estudo com base na Décima Urbana de 1809. Revista Anais do Museu Paulista: história e cultura material, São Paulo, volume 13, janeiro a junho, 2005.

${ }^{12}$ AMWL, Atas da Câmara, volume XXIV, página 236.
} 
dia 13 de setembro quando é feita nova vistoria e realizado o arruamento do terreno. Em 17 de setembro, no entanto, a Câmara pede que a requerente não construa morada até que seja mandada a carta de data, o que acontece somente no dia 5 de outubro de 1830, quando, finalmente, Dona Gertrudes Maria Siqueira conquista o terreno. ${ }^{13}$

O mercado imobiliário, além de ser um dos termômetros para demonstrar a lentidão, a fraqueza e o empobrecimento da Câmara, também revela outra peculiaridade: assim como a já citada Dona Marianna Forte - uma das maiores proprietárias de terra da cidade de São Paulo - outras mulheres estão fortemente inseridas na economia formal. Dona Florisbela de Toledo Santiago, em 22 de julho de 1835 pede licença à Câmara para continuar o comércio do seu antigo marido, em sociedade com Antônio Gomes Paixão. Seu requerimento é aprovado em 28 do mesmo mês. ${ }^{14}$ Anna Maria do Carmo também, em 9 de junho de 1834, pede licença para vender armas. ${ }^{15}$ Elas são exemplos de mulheres que possuíram comércio na cidade oitocentista.

Grande parte destas comerciantes também vendia seus produtos para obras na cidade realizadas pela Câmara, o que ajudava a manter um diálogo vivo entre o projeto urbano do Código de Posturas e a população que vivia de comércio. Quando vislumbramos mulheres que estavam à frente de negócios, faz-se pensar ainda mais em uma população que vivia em situação financeira pouco privilegiada, ainda que não totalmente empobrecida, uma vez que tanto as mulheres solitárias quanto aquelas que precisavam somar seus rendimentos aos do cônjuge, normalmente estavam vivendo sob condições difíceis. Dona Joaquina Engracia Alvim, ${ }^{16}$ mais de uma vez vendeu material para obras da cidade; assim como Dona Gertrudes Jacinta, ${ }^{17}$ ou então o caso de Dona Gertrudes Thereza ${ }^{18}$ que alugou a mão de obra de seu escravo para que ele trabalhasse

\footnotetext{
${ }^{13}$ AMWL, Atas da Câmara. Seguindo as datas acima, a requerente aparece nos registros da Câmara na respectiva ordem (trata-se do volume XXV): página 87; página 117; página 130; página 132; página 200; página 218; página 220.

${ }^{14}$ AMWL, Atas da Câmara, volume XXVIII, página 104.

${ }^{15}$ AMWL, Atas da Câmara, volume XXVII, páginas 423-424.

${ }^{16}$ Um exemplo: AWML: Papéis Avulsos, etiqueta 35, página 30.

${ }^{17}$ AMWL, Papéis Avulsos, etiqueta 36, página 42.

${ }^{18}$ AMWL, Papéis Avulsos, etiqueta 40, página 142.
} 
como pedreiro em obra realizada pela municipalidade - outro expediente também muito usado por parte da população.

Em grande parte, esta parcela da população que vivia com dificuldades financeiras, que tinha alguns poucos escravos, uma moradia e um emprego que rendia o sustento, representava uma porção demográfica que manteve um diálogo intenso com as propostas municipais. Não somente de conflitos e resistências viveu a população paulista menos remediada e os funcionários da Câmara. Entre o atrito contínuo, houve contratos, conchavos, trocas de ambas as partes. A Câmara necessitava desta parcela demográfica não somente para aplicar seu projeto urbano, mas também, uma vez estando empobrecida a instituição, para atividades banais da cidade. Eventos ou serviços extras que a municipalidade não dava conta eram mantidos por estas pessoas, de modo que saía mais barato pagar empregados eventuais não tão qualificados para a tarefa do que contratar empregados fixos. E, por uma série de contingências históricas e culturais, as mulheres tornaram-se personagens principais nestes ramos. Personagens como Anna Josepha ou Maria Joaquina da Silva que, em 8 de junho de 1825 , receberam pelas despesas que tiveram na organização das festividades da festa de Corpo de Deus. ${ }^{19}$ Sabendo que as mulheres representavam $40 \%$ dos chefes de fogos da cidade em $1820,{ }^{20}$ dá-se para intuir como se espalhavam em diversas atividades citadinas.

Para um chefe de família paulista oitocentista, realizar trabalhos eventuais ajudava a manter uma casa, quitar despesas ou provar renda na hora de conseguir terrenos, o que não era tarefa fácil. Segundo as Posturas Municipais, somente depois da vistoria, do alinhamento e arruamento do terreno requerido é que se dava a doação. Pessoas que já tinham terrenos, mas que não se enquadravam nas exigências dos Códigos da cidade deveriam também pedir os tais alinhamentos ou arruamentos, assim como o caso de Escholastica Maria de São José ou, então, o de Maria Fernanda da Conceição, que possuíam terrenos no Brás, e requerem no dia 20 de outubro de 1830 as reformas necessárias para que pudessem se enquadrar nas Posturas. ${ }^{21}$ Mesmo que a fiscalização municipal não fosse

\footnotetext{
${ }^{19}$ AMWL, Atas da Câmara, volume XXIII, páginas 343-345.

${ }^{20}$ Para dados demográficos, ver: MARCíLIO, Maria Luiza. A cidade de São Paulo - povoamento e população, 1750 - 1850. São Paulo: EDUSP, 1974.

${ }^{21}$ AMWL, Atas da Câmara, volume XXV, páginas 235-236.
} 
a mais adequada, não foram raros os casos como o de Dona Anna Mendes que, não tendo preservado a sua casa de taipa da rua Nova em boas condições, viu parte de sua moradia ser posta abaixo em $1821,{ }^{22}$ época em que ainda se exigia menos da aparência urbana do que após a revisão dos Códigos em 1830.

Se por um lado os funcionários encarregados pela Câmara para fiscalizar não eram sempre imparciais e tampouco suficientes para suas funções (tal o caso dos Juízes de Paz), os vereadores possuíam o apoio de outros "fiscais" bastante assíduos no seu trabalho: os próprios moradores. Está claro que em uma cidade tão provinciana, de instituições ainda pouco estruturadas e de altos níveis de pobreza como a São Paulo oitocentista, a proliferação dos trabalhos informais impulsionava redes de sociabilidade entre vizinhos, amigos e desconhecidos que geravam grande parte das organizações sociais existentes. ${ }^{23}$ Ao mesmo tempo, portanto, que uma pessoa mantinha com as pessoas próximas, os viandantes que cruzavam seu caminho e com aquelas com quem tinha comércio, diversas redes de convívio que garantiam sua sobrevivência, esta mesma pessoa criava, ao seu redor, possíveis inimigos. Os casos de denúncia povoam as vereanças paulistas e nos contam da incapacidade fiscal da cidade, assim como também da rica e complexa teia de sociabilidades na qual pequenos poderes sociais e influências com pessoas mais importantes ajudavam a construir diversas hierarquias urbanas muito diversas da estratificação vertical do poder.

As denúncias muitas vezes giravam em torno de um problema comum na cidade: os formigueiros. É muito fácil encontrar nas Atas da Câmara problemas relacionados às formigas da cidade. Pelo que consta, tais insetos invadiam os quintais de quase todas as casas e dificilmente o problema era controlado com eficácia. No entanto, por vez ou outra, algum formigueiro crescia tanto que as formigas começavam a incomodar o quintal vizinho. Dona Maria Fontes, Rosa Tavares e Anna Maria Conceição são apenas algumas das pessoas que foram acusadas, na década de 1830 , de terem formigueiros em seus quintais. ${ }^{24}$

\footnotetext{
${ }^{22}$ AMWL, Atas da Câmara, volume XXII, página 538.

${ }^{23}$ Sobre a sociabilidade e a função dos papéis informais da cidade, ver: DIAS, Maria Odila Leite da Silva. Quotidiano e poder em São Paulo no século XIX. São Paulo: Ed. Brasiliense, 1984.

${ }^{24}$ AMWL, Papéis Avulsos, etiqueta 34, página 124.
} 
Curiosamente, a maior parte das denúncias, ocorridas nas décadas de 1820 e de 1830 e registradas nas Atas da Câmara, recaía sobre mulheres, como no caso de Dona Gertrudes Maria de São José, que no dia 15 de abril de 1830 recebe um encaminhamento, um aviso, contra ela informando que em seu terreno havia barreiras públicas, ${ }^{25}$ ou seja, limites do traçado urbano pertencentes à municipalidade. Mais tarde, em 26 de novembro de 1832, a mesma infratora é denunciada pela contravenção das posturas condizentes ao reboque e à caiação dos muros. ${ }^{26}$ A predominância, ao menos aparente, do gênero feminino nas denúncias, talvez se deva pelo fato de haver muitas mulheres menos remediadas que possuíam terrenos, e que cuja situação financeira impossibilitava-as de preservarem suas casas conforme exigia as Posturas; ou, então, por outro lado, por elas participarem majoritariamente destas redes de sociabilidade indispensáveis à sobrevivência nos trabalhos informais, o que geravam tanto oportunidades quanto inimizades e possíveis conflitos. Grande parte das mulheres também teimava em preservar costumes nas vestimentas, nas moradias e nos hábitos rotineiros, o que podia incomodar deveras pessoas que estavam próximas, como vizinhos de casa ou comércio. Fato é que a Câmara contava muito com estas denúncias para fiscalizar a cidade. E o importante de se constatar nestas ocorrências é que, movidos por ambições pessoais, os delatores também acabavam por ajudar a municipalidade numa tarefa da qual, sozinha, ela seria incapaz.

Enxergando a questão de outra maneira, a denúncia também evidencia níveis de conhecimentos legislativos da população. Mesmo que este conhecimento fosse parcial e muitas vezes deturpado nos labirintos da transmissão oral, o diálogo entre Câmara e os requerentes amparava-se quase sempre nos Códigos de Posturas municipais. Também por isto é interessante quando tratamos das mulheres, na grande maioria analfabetas e pouco instruídas, e percebemos graus de consciência e conhecimento legislativo e político. Há o caso revelador de Dona Jacinta Candira de Carvalho, que no dia 26 de julho de 1833 consegue se absolver de pagar multa por ter infringido o artigo $4^{\circ}$ do Código de Postura, relativo a edificar sem antes ter alinhado o terreno. Seu argumento de defesa é que ela edificara em alicerces antigos, ${ }^{27}$ ou seja, que enxergava nas novas

\footnotetext{
${ }^{25}$ AMWL, Papéis Avulsos, etiqueta 32, página 215.

${ }^{26}$ AMWL, Atas da Câmara, volume XXVII, página 42.

${ }^{27}$ AMWL, Papéis Avulsos, etiqueta 52, página 181.
} 
posturas municipais brechas para construir em cima de velhas moradias, preservando fundações que remontavam a um tempo no qual não se era necessário alinhar o terreno para construir. Assim também, Dona Jacinta Candira de Carvalho, como outras mulheres, encontraria nas novas posturas espaços pelos quais fosse capaz de perpetuar antigas tradições, da mesma forma que conseguiria, mesmo que ultrapassando as fronteiras das mais recentes imposições urbanas, reestruturar sua vida a partir de hábitos velhos tão bem sedimentados.

Anna de Jesus Maria, por sua vez, responde à Câmara em 4 de junho de 1829 alegando que o encanamento da rua do Rego era da alçada municipal, e que com isto ela se isentava dos pagamentos exigidos. ${ }^{28}$ Da mesma forma autoritária, Maria Borges encaminha um requerimento aos vereadores em 20 de janeiro de 1831, pedindo providências quanto aos incômodos que lhe causavam a limpeza da cadeia, junto à sua casa. ${ }^{29}$ Anna Maria do Carmo, por sua vez, em $1^{\circ}$ de março de 1832, queixa-se que o fiscal estava cobrando quantias exorbitantes nas avenças. Neste caso, o fiscal se explica e a requerente perde a causa. ${ }^{30}$

Quando se tratava de uma mulher melhor posicionada socialmente, a base legal de sua argumentação vinha sempre mais bem formulada, seja por seu conhecimento, seja por sua condição de pagar um procurador. Os menos remediados reconheciam a Câmara Municipal como um órgão legítimo para que eles defendessem seus direitos, mas tinham mais dificuldades de conseguir o amparo legal, o que, de qualquer modo, não os impedia de recorrer às suas causas.

\section{Identificando os legados de poder}

Como se vê, no prédio da Câmara, nas vereanças diárias, passavam muitos fragmentos de histórias femininas. Sua presença é ainda mais instigante quando sua atuação, quase pulsante, contrasta com a iconografia do século XIX ou com a historiografia mais tradicional, nas quais estas mesmas mulheres parecem não existir. Inserindo-as na imagem daquela cidade de então, é possível começar a desconfiar das fotografias oitocentistas, das pinturas, dos documentos oficiais. As próprias Atas da Câmara, escritos políticos e, portanto, teoricamente mascu-

\footnotetext{
${ }^{28}$ AMWL, Papéis Avulsos, etiqueta 29, página 169.

${ }^{29}$ AMWL, Papéis Avulsos, etiqueta 35, páginas 28-29.

${ }^{30}$ AMWL, Papéis Avulsos, etiqueta 41, página 198.
} 
linos, dão apenas impressões de mulheres. São sugestões que requerem análise, imaginação. Sem o cuidado necessário, sem a construção minuciosa que suas histórias requerem, estes vultos femininos parecem coadjuvantes da história urbana ou, quando muito, personagens que estão reagindo a arbítrios da lei. Mas se pensarmos que cada uma daquelas personagens tem uma história é possível enxergar suas pequenas aparições nas vereanças como a ponta de um iceberg. Sua presença, então, passa a ser recheada de significados, de crenças, de necessidades e de ambições. Suas ações finalmente são entendidas tal como o que foram, e não mais simples reações a algo ou alguém. Suas vidas, por vezes muito simples, penetram no cerne e não nas fímbrias da história da cidade, dialogando com todos os outros personagens desta trama, criando um enredo diferente do que seria sem sua presença. Ao final das contas, inseri-las historiograficamente é garantir sua presença efetiva na história da cidade. É compreender o sentido da historiografia mais tradicional que, deparando-se com outras questões e outros vieses metodológicos, acabou por excluí-las ou marginalizálas, e, então, redirecionar o olhar histórico. É rever conceitos e imagens da São Paulo oitocentista, não somente para preenchê-los com figuras femininas, mas para transformá-los com a experiência destas mulheres tão atuantes nesta sociedade. Não podemos entendê-las como um adendo à história citadina, uma vez que um adendo não faria parte do corpo desta história. Temos que enxergálas como figuras inseridas na sociedade e historiograficamente transformadoras, mesmo que a imagem que delas se criou possa ter passado, por muito tempo, invisível, esquecida ou borrada. ${ }^{31}$ E mesmo que já em 1820 as mulheres representassem o incrível número de $40 \%$ dos chefes de fogo de toda a cidade, e, em 1833 elas representassem quase que o mesmo número de $40 \%$ de chefes de fogos somente na região central da Sé, ${ }^{32}$ vale fazer constar algumas das mulheres que entre 1820 e 1832 pediram terrenos para a Câmara, a fim de personificar

\footnotetext{
${ }^{31}$ Quanto à historiografia sobre as mulheres em suas tendências ao longo das últimas décadas, ver: SCOTT, Joan. "História das mulheres". In: BURKE, Peter (org ). A escrita da Histórianovas perspectivas. São Paulo: Ed.Unesp, 1992. O descortinar da vida destas mulheres paulistas já vem realizado feito pela historiografia mais comprometida com esta questão desde Maria Odila Leite da Silva Dias, de modo que a temática tem tido grandes evoluções analíticas.

${ }^{32}$ AMWL, Papéis Avulsos, etiqueta 56, páginas 213-228. Este documento fornece uma relação do número de fogos e chefes de família da freguesia da Sé. Sistematizando os dados, cheguei ao número que conta para as mulheres quase $39 \%$ dos chefes de fogos.
} 
levemente estes valores quantitativos. São elas: Dona Maria Álvares de Siqueira, Mathilde Maria, Anna Maria Conceição, Dona Anna Rosa Álvares Machado, Anna Maria de Jesus, Dona Gertrudes Maria de Siqueira, Dona Benta Maria de Siqueira, Maria Fernandes da Conceição, Dona Gertrudes Thereza Bueno, Rufina Maria da Anunciação, Policena Maria de Jesus, Anna Francisca, Maria Theodora dos Reis, Claudina Gabriela, Joana Maria, Maria Joaquina, Carolina Maria das Dores, Ana Joaquina do Prado, Custodia Maria de Souza, Maria Antonia de Vasconcelos, Joana Francisca, Joana Maria, Ignez de Jesus, Floriana Jacintha da Conceição, Quitéria Maria do Espírito Santo, Appolinia Maria e suas filhas, Dona Maria do Rosário, Dona Anna Joaquina de Oliveira e Lacerda, Anna Francisca, Dona Manuela do Nascimento, Ana Rita de Oliveira, Gertrudes Maria Eufrosina, Maria Gertrudes, Thereza de Jesus, Maria Antônia de Santa Rita, Maria Barbosa, Beatriz Felizarda da Conceição, Maria Antônia de Vasconcelos, Ana Joaquina do Prado, Custódia Maria de Souza, Agneda Maria da Silva e assim por muito mais adiante. ${ }^{33}$

Grande parte do trabalho informal ou clandestino era praticado por mulheres, principalmente no que concerne ao pequeno comércio. $\mathrm{O}$ abastecimento de gêneros alimentícios de São Paulo carecia muito das vendeiras de rua, fossem elas trabalhadoras livres ou escravas de ganho. ${ }^{34}$ Este tipo de serviço jamais desapareceu, mesmo tendo sofrido constantes ataques da municipalidade. A Câmara não buscava destruir a prática da venda, mas regulamentar, definir o local, receber impostos, saber se utilizar da força e organização deste comércio para criar, muito mais tarde, instituições municipais, tal como a feira-livre. ${ }^{35}$ Contudo, os vereadores nunca conseguiram controlar totalmente os ambulantes, não somente porque estes comerciantes não tinham condições de se enquadrar nas leis do comércio legalizado, mas também porque este tipo de atividade remontava a uma série de tradições e estava vinculada a diversos níveis muito profundos de poder social. Se em 1827, no dia 6 de junho, um ofício do juiz

\footnotetext{
${ }^{33}$ Nomes recolhidos na documentação das Atas da Câmara ou dos Papéis Avulsos, ambos conjuntos documentais localizados no Arquivo Municipal Washington Luis, entre os anos de 1820-1841.

${ }^{34}$ DIAS, Maria Odila Leite da Silva. Op. cit.

${ }^{35}$ Sobre a legitimação das leis e das instituições urbanas, ver: ROLNIK, Raquel. A cidade e a lei-legislação, política urbana e territórios na cidade de São Paulo. $2^{\mathrm{a}}$. ed.. São Paulo: Studio Nobel: FAPESP, 1999.
} 
almotacé pedia a transferência para o Pátio de São Gonçalo das vivandeiras e quitandeiras de quitandas volantes, ${ }^{36}$ os memorialistas do começo do século ainda lembravam destas mulheres de comércio andarilho perambulando impunemente por onde quisessem ou precisassem suas vendas.

$\mathrm{Na}$ rotina diária de uma vendedora ambulante, as redes de sociabilidade eram indispensáveis ao seu sucesso. Ainda mais em uma cidade tão pequena que tanto os mais quanto os menos remediados podiam eventualmente compartilhar os mesmo lugares e influências, as amizades que geravam trocas de favores eram essenciais. Munidos muitas vezes somente dos conhecimentos sobre seu ofício, que eram principalmente legados pelos pais, avós, amigos ou desconhecidos mais velhos, os comerciantes confiavam às redes de sociabilidade grande parte do sucesso nas vendas. Disto resultavam hierarquias sociais importantíssimas, nas quais analfabetos, pessoas muito pobres, escravos ou outros igualmente desclassificados adquiriam status, importância.

Junto aos vendedores ambulantes, reuniam-se outros personagens sociais como os feiticeiros ou as parteiras. ${ }^{37}$ Carregando tradições quase hereditárias, eles alcançavam um prestígio social e uma espécie de poder horizontal que não se desfizeram jamais durante o século XIX . Mesmo quando São Paulo começara a crescer vertiginosamente por conta do dinheiro da cafeicultura, a influência destes personagens urbanos manteve-se ou modificou-se, mas dificilmente desapareceu. ${ }^{38}$ No seio de uma sociedade moderna como a paulista do começo do século XX, os feiticeiros e as parteiras muitas vezes recebiam mais confiança da população do que os médicos. Assim também, as vendedoras ambulantes continuavam nos largos, nas ruas, nas portas das casas garantindo enorme parcela do comércio urbano. Obviamente que com o crescimento e a modernização da cidade no século XX, aos poucos a força destes serviços decaiu. Contudo, por todo século XIX, ainda mais na primeira metade, estas pessoas estavam muito ativas.

\footnotetext{
${ }^{36}$ AMWL, Atas da Câmara, volume XXIV, página 82.

${ }^{37}$ Para saber sobre feiticeiros e a importância dos poderes sociais advindos de atividades escusas e informais, ver: WISSENBACH, Maria Cristina Cortez. Ritos de magia e sobrevivência: sociabilidades e práticas mágico-religiosas no Brasil (1890-1940). São Paulo: Tese de doutoramento - Departamento de História-FFLCH/USP, 1997.

${ }^{38}$ Ver trabalhos de memorialistas do começo do século XX, como: AMERICANO, Jorge. São Paulo naquele tempo (1895 - 1915). São Paulo: Carrenho Editorial / Narrativa Um / Carbono 14, 2004.
} 
Um dos grupos interessantes dentre os que mantinham certas relações de poder social era o dos escribas, principalmente aqueles pertencentes a camadas menos privilegiadas da população. Servindo de ponte entre a cultura oral e a escrita, este grupo possuía na linguagem um elemento de ascensão e afirmação que ultrapassava os limites do poder social, uma vez que eles próprios dominavam as ferramentas dos mais ricos, dos homens influentes. Transcrevendo as palavras da enorme porção analfabeta da população, eram os escribas que manejavam o instrumento fundamental que legitimava as leis e os acordos citadinos. Esta habilidade com a palavra escrita, não somente era respeitada pelos grupos pouco remediados, dos quais muitos escribas também faziam parte, mas também era a representação primordial da ligação entre os universos formal e informal. ${ }^{39}$

Se aproximarmos ainda mais o foco de análise e dirigi-lo para a intimidade das relações sociais da população, acabamos por ver, então, que estes poderes horizontais aparentemente paralelos ao poder central, atravessavam a esfera social para se infiltrar na política e verticalizar suas influências. O contato diário nas ruas era percorrido por uma série de trocas de favores, de relações informais mantidas por todo o tipo de pessoa, de escravos a camaristas. De fato, a questão de inserir grupos menos privilegiados nas atividades formais de São Paulo aparece com mais vigor quando entendemos o inverso, ou seja, a inserção da política nas atividades citadinas vistas como escusas e informais. Se uma parte da política acontecia antes por interesses individuais, impulsionados por um jogo de trocas, é mais fácil entender como grupos de ambulantes, feiticeiros, parteiras ou outros penetravam nas questões da Câmara Municipal. Quanto maior era rede de influência e o poder social de uma pessoa, quanto maior a sua proximidade com os vereadores, mais diretamente também ela podia fazer parte da política paulista. O que a frieza das leis, a oficialidade dos documentos e os limites de uma imagem não nos conta desta sociedade paulista é sobre o indomável aspecto individual, as ambições, crenças e realizações pessoais que comprometem desde os vereadores até os menos remediados na construção e transformação da história da cidade.

\footnotetext{
${ }^{39}$ Para saber mais sobre os poderes da palavra escrita, ver: WISSENBACH, Maria Cristina Cortez. "Cartas, procurações, escapulários e patuás: os múltiplos significados da escrita entre escravos e forros na sociedade oitocentista brasileira". Revista Brasileira de História da Educação, número 4, dezembro de 2002, pp. 103 a 122.
} 
Assim é o caso de Appolinaria Maria, que no dia 17 de julho de 1832, requer que a Câmara dê para ela e não para o seu inimigo, José Ignácio, o terreno do fundo de seus quintais. ${ }^{40}$ Também o acontecimento de 4 de fevereiro do ano seguinte, no qual Dona Bernarda Maria Bueno pede que o sargentomor Albuquerque sirva de juiz em uma causa sua em que o juiz e o suplente são suspeitos. ${ }^{41} \mathrm{O}$ mesmo ocorre com Agueda D’Aro que, em 9 de maio de 1840, pede que se nomeie um juiz municipal para uma ação contra Joaquim J. Pedro, uma vez que o juiz atual, segundo ela, era suspeito. ${ }^{42} \mathrm{E}$ assim por diante, os problemas íntimos, a relações informais povoam as vereanças paulistas. Por um lado, a população transportava para a Câmara vínculos e poderes sociais, e por outro, os vereadores mantinham com os requerentes um diálogo muito íntimo e casual. Neste jogo de mão dupla, no qual interesses eram permutados em níveis da informalidade, a política paulista acontecia.

Em 1832, com o Ato Adicional, a Câmara Municipal perde grade parte da sua autonomia, ficando ainda mais subordinada aos mandos da Assembléia Provincial. Em 1841, então, com a Reforma do Código do Processo, os Juízes de Paz são substituídos por funcionários do governo imperial, em uma clara tentativa de centralização. Enfraquecidos e direcionados aos pequenos problemas administrativos de cunho urbano, os vereadores se voltam ainda mais precisamente para as questões internas das vereanças. Sabendo disto, e enxergando o interior confuso e híbrido desta instituição municipal de São Paulo, vemos que, pelo menos até 1870, estas questões internas com as quais os vereadores se ocupavam, e que circulavam pela Câmara, constantemente diziam respeito aos conchavos, às trocas, aos jogos de amizade e às picuinhas rotineiras ou ambições individuais da população. A mescla entre formal e informal, entre público e privado permaneceu ainda por longo tempo. Portanto, olhar por dentro da Câmara paulista de quase todo o século XIX é enxergar pessoas, intenções e acontecimentos muito diferentes do que se possa imaginar quando apenas a contemplamos de fora e de longe de seu o prédio.

\footnotetext{
${ }^{40}$ AMWL, Atas da Câmara, volume XXVI, páginas 492-493.

${ }^{41}$ AMWL, Atas da Câmara, volume XXVII, página 105.

${ }^{42}$ AMWL, Atas da Câmara, volume XXXIII, página 36.
} 